\title{
Acontecimento sideral e a governamentalização do planeta: notas sobre as atualizações dos dispositivos de poder nas sociedades de controle
}

\section{Leandro Siqueira ${ }^{1}$}

Resumo: A experiência humana de abandonar a Terra para explorar o espaço sideral implicou em retornos que impactaram a forma das contemporâneas sociedades se organizarem, alterando inclusive o modo como essas sociedades compreendem o seu planeta de origem. Neste trabalho, procuramos analisar os efeitos do acontecimento sideral para a configuração dos dispositivos de poder nas chamadas sociedades de controle, dando continuidade à sugestão analítica proposta pelo filósofo Gilles Deleuze sobre o atual agenciamento social. Entre esses efeitos destacamos, primeiramente, a contribuição da exploração espacial para a emergência do corpo-planeta, no momento em que a Terra surge como uma nova superfície a ser recoberta por investimentos políticos. Em segundo lugar, chamamos a atenção para o processo de governamentalização do planeta, acelerado graças à disponibilidade de tecnologias espaciais empregadas em larga escala para o monitoramento e a gestão dos fluxos planetários, assinalando a emergência do planeta como corpo político.

Palavras-chave: Exploração espacial; monitoramentos; governamentalidade planetária; sociedades de controle.

$1 \quad$ Universidade Metropolitana de Santos (UNIMES) - Santos - Brasil - ladps@uol.com.br 


\section{Outer Space event and planetary governmentalization: remarks on the upgrading of power dispositifs in societies of control}

Abstract: The historical endeavor of abandoning Earth to explore outer space has yielded socio-technical spinoffs that have had lasting impacts upon the ways in which contemporary societies organize themselves, including a changed understanding of their very planet of origin. The main aim of the present article consists in analyzing the effects of the outer space event upon the reconfiguration of the power dispositifs in the so-called societies of control, along the lines of the analytical categories proposed by Gilles Deleuze. At first, this paper highlights the contribution of space exploration to the advent of the planet-body, at a time when the Earth emerges as a new surface to be covered by political investments. Secondly, it draws attention to the process of planetary government, facilitated by the availability of space technologies for monitoring and managing emphatically global flows, marking the materialization of the planet as a political body.

Keywords: Space exploration; monitoring; planetary governmentality; societies of control.

Ao toque de um dedo, o aplicativo Earth-Now ${ }^{2}$ informa uma série de dados climáticos da Terra coletados em tempo quase real pela constelação de satélites da agência espacial estadunidense NASA. Na tela do smartphone, abre-se um modelo tridimensional com vários "sinais vitais" do planeta, como o nível de dióxido de carbono, de ozônio, da altura do mar e anomalias gravitacionais para o usuário interessado em acompanhar os efeitos das Mudanças Climáticas. Além disso, alertas avisam a ocorrência dos mais diversos eventos geoclimáticos sobre o globo. Em março de 2018, o Earth-Now destacava a erupção do vulcão Kadovar, em Papua, Nova Guiné, e a tempestade de areia que atingia a Arábia Saudita e o Iêmen. Ao clicar sobre eles, o modelo tridimensional da Terra gira até que imagens de satélite mostrem o evento. "O mundo inteiro na palma das mãos", promete a NASA. ${ }^{3}$

Impressiona constatar que meio século após astronautas terem pioneiramente visualizado a olhos nus o seu planeta, a Terra esteja disponível para que qualquer pessoa possa observá-la, com vistas a colaborar para a sua proteção

20 aplicativo Earth-Now pode ser visualizado na página $<$ https://climate.nasa.gov/earth-now $>$. Acesso em: 03 jun. 2019.

3 Disponível em: <https://www.nasa.gov/topics/earth/features/earth20120319.html>. Acesso em: 03 jun. 2019. 
em tempos de ameaças à continuidade da existência humana causadas pelo aquecimento global. A disponibilidade de informações sobre a Terra, a possibilidade de monitorá-la e, ainda mais, a noção de que o planeta seria um corpo passível de ser controlado e, até mesmo, melhorado, são retornos do acontecimento sideral que transformaram o modo do humano se relacionar com seu planeta.

Denominamos acontecimento sideral ${ }^{4}$ o duplo movimento de abandono e retorno à Terra propiciado a partir da segunda metade do Século XX pelas tecnologias espaciais. Ao mesmo tempo em que essas tecnologias permitiram enviar astronautas à órbita terrestre e à Lua, elas inesperadamente possibilitaram a "descoberta" da Terra. Cabe salientar que, quando nos referimos a tecnologias, não nos limitamos a pensar apenas em artefatos técnicos; antes disso, como observa o filósofo Gilles Deleuze (1986), tomamo-las como produções sociais, ou seja, expressões de agenciamentos coletivos. O acontecimento sideral é aqui pensado como uma singularidade irrompida na segunda metade do Século XX, cujos efeitos continuam a incidir indiscriminadamente sobre os viventes, as sociedades e o planeta. Observamos seus efeitos como algo da ordem do incidental e do imprevisível, capazes de produzirem inesperadas mutações.

Neste trabalho, a chamada exploração espacial é problematizada por uma perspectiva política que busca abrir as Ciências Sociais para a análise das múltiplas relações estabelecidas pelas forças envolvidas no processo que culminou na projeção do vivente para o espaço exterior à Terra. Também procuramos prestar atenção ao que retorna da projeção para o sideral, sobretudo aquilo que impactou a configuração dos dispositivos de poder nas atuais sociedades.

Com base na análise do acontecimento sideral, pretendemos contribuir para a problematização do contemporâneo agenciamento coletivo denominado por Deleuze de sociedades de controle. Para tanto, desenvolveremos este artigo em três movimentos. No primeiro, expomos alguns elementos propiciados pela exploração sideral que consideramos fundamentais para se pensar as sociedades de controle. Em seguida, examinamos como o acontecimento sideral contribuiu para configurar uma nova noção da Terra que atende a desafios e urgências colocadas pelo atual agenciamento coletivo. Por fim, apontaremos o processo de

4 A noção de acontecimento aparece em vários momentos na produção intelectual de Michel Foucault. Interessa-nos aquela que o autor elaborou em seus estudos sobre Nietzsche. No texto "Nietzsche, a genealogia e a história", Foucault (1979:15) afirma ver o acontecimento como a aguda irrupção de uma singularidade. Neste sentido, acontecimentos não são da ordem da teleologia e nem dizem respeito a fatos ou eventos, mas implicam em descontinuidades a serem espreitadas na agonística das forças. 
governamentalização do planeta, como sinal indelével da projeção da racionalidade neoliberal em escala global.

Figura 1 - Imagens do aplicativo Earth-Now: segundo a NASA, "o mundo inteiro na palma das mãos"
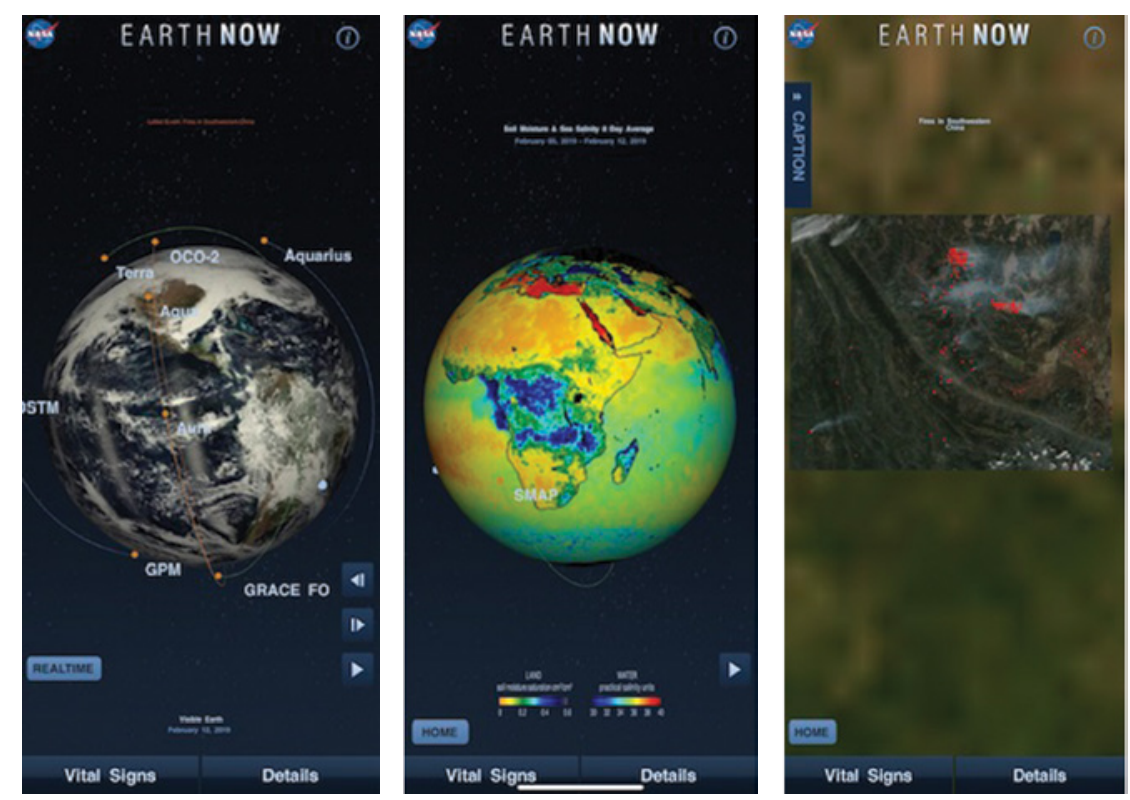

Fonte: EarhNow/NASA

\section{1 - Na guerra, procedências siderais do controle}

Na virada dos anos 1980 para os 1990, o filósofo Gilles Deleuze apresentou a noção de sociedades de controle com o intuito de descrever mudanças ocorridas nos diagramas das sociedades ocidentais ao longo da segunda metade daquele século. Deu o nome de controle a novas relações de poder que se caracterizam por operar de forma "contínua e ilimitada", mediante "comunicação instantânea" (Deleuze, 1990: 236-37), em resposta a urgências colocadas pelo governo de populações em meios abertos (Deleuze, 2014).

Deleuze buscou compreender as contemporâneas sociedades focando-se em descontinuidades observadas no funcionamento dos mecanismos de poder. Sua análise se baseou na percepção de que os dispositivos disciplinares do Século XVIII, anteriormente estudados pelo filósofo Michel Foucault, estariam em crise e não tardariam a ser suplantados. Segundo Deleuze, enquanto as sociedades disciplinares recorriam a tecnologias de poder baseadas em confinamentos ou sistemas fechados (escola, prisão, hospital, fábrica etc.) para compor as forças 
de multiplicidades pouco numerosas em função de uma utilidade almejada, 0 controle se voltaria para a administração de populações, de grandes multiplicidades de humanos e não humanos, dispostas em espaços abertos. No lugar de muros, as sociedades de controle privilegiariam cálculos probabilísticos e a produção de zonas de frequência para governar o conjunto social.

Em seus poucos escritos sobre 0 controle, Deleuze o relacionou às máquinas cibernéticas, como os computadores, ao uso de cartões que gerenciam acessos, ao elemento químico silício, mas nunca mencionou a exploração do espaço sideral. Todavia, acreditamos ser pertinente examinar a relação entre sociedades de controle e exploração sideral para mostrar que tais sociedades também poderiam ter como procedência o acontecimento sideral (Siqueira, 2015). Neste sentido, exploramos genealogicamente a possibilidade de pensar a projeção para o sideral, ocorrida desde o fim dos anos 1950, como um dos "mil acontecimentos agora perdidos" a ser resgatado para compreender como se deu "a entrada em cena das forças" que teriam configurado os dispositivos de poder específicos das atuais sociedades de controle (Foucault, 1979).

Embora a emergência dessas sociedades tenha se dado no mesmo momento histórico em que se efetivou a exploração sideral, a aproximação que estabelecemos não se justifica simplesmente com base em argumentos cronológicos. Para avançar nesta análise, problematizamos os efeitos da Segunda Guerra Mundial na configuração das sociedades de controle e, dentre eles, sublinhamos os aportes trazidos pelo acontecimento sideral para a instauração de tecnologias de governo dos espaços abertos que caracterizam as relações de poder nestas sociedades.

Em seu principal texto sobre o tema intitulado "Post-scriptum sobre as sociedades de controle", Deleuze é sucinto ao se referir à emergência das sociedades de controle. Sem dar muitos detalhes, afirma que as "novas forças" do controle se "instalavam lentamente" e se "precipitariam depois da Segunda Guerra Mundial” (1990: 241, grifo meu). Outra referência para o estudo das sociedades de controle, o politólogo Edson Passetti (2003) também destaca sua relação com o conflito mundial. Para este autor, a explosão das bombas atômicas sobre Hiroshima e Nagasaki, que colocaram fim à guerra no Pacífico, é o evento que sinaliza a entrada em cena dessas sociedades.

Tratam-se, portanto, de duas pistas para se pensar a emergência do controle. Note-se que o filósofo utilizou o verbo "precipitar" (em francês, précipiter) para fazer referência a mutações nas economias de poder. Este vocábulo tem entre seus principais significados a ideia de queda, além da ideia de aceleração do ritmo. Embora não utilize o termo "precipitar", Passetti também se remete 
ao mesmo movimento de cima para baixo ao associar a instalação das sociedades de controle às bombas atômicas jogadas de aviões bombardeiros estadunidenses sobre as cidades japonesas. A essas procedências trazidas pelos autores acrescentamos mais uma, que também desabou dos céus: os retornos da exploração sideral.

O fim da Segunda Guerra Mundial reconfigurou o equilíbrio da política internacional com a instauração de um sistema bipolar capitaneado pelas superpotências vitoriosas no conflito mundial: os Estados Unidos da América (EUA) e a União das Repúblicas Socialistas Soviéticas (URSS). No pós-guerra, não tardou para que a divisão do mundo nos blocos que opunham as chamadas "sociedades abertas" (capitalistas) às "sociedades fechadas" (socialistas) conduzisse ao enfrentamento planetário que ficou historicamente conhecido como Guerra Fria. Esse conflito diferenciou-se de outros grandes enfrentamentos mundiais por não se tratar de um combate direto e declarado, mas por se estabelecer como um confronto predominantemente estratégico, balizado pela potência destrutiva acumulada pelos arsenais nucleares acumulados das superpotências.

A competição pela hegemonia planetária travada entre EUA e URSS durante a Guerra Fria acelerou o aperfeiçoamento de tecnologias que permitiram aos Estados desenvolverem armas capazes de atingir alvos em outros continentes e, ao mesmo tempo, abandonar a superfície do planeta, dando início às corridas armamentista e espacial. A tecnologia que propiciou a criação de mísseis balísticos intercontinentais foi a mesma que possibilitou a construção de foguetes para as viagens espaciais. Embora seu aprimoramento tenha se dado nas superpotências a leste e a oeste, a pioneira utilização de foguetes remonta à Segunda Guerra Mundial, protagonizada pela Alemanha nazista.

Na tentativa de conter o avanço das tropas Aliadas, já no período final do conflito mundial, o Terceiro Reich decidiu utilizar sua "arma de represália", o foguete/bombardeiro Vergeltungswaffe 2 (V2). Os V2 nazistas foram desenvolvidos a partir de 1938 pela equipe do fusólogo Wernher von Braun, que mais tarde tornou-se mentor do programa espacial estadunidense. Entre 1944 e 1945, mais de 3 mil V 2 foram lançados contra Inglaterra, França, Bélgica e Holanda. Com a queda do Reich, os V2 que restaram, assim como outras tecnologias e também técnicos alemães, foram "espoliados" pelos exércitos estadunidenses e soviéticos. Nesses países, serviram de modelo para o desenvolvimento de mísseis e de veículos lançadores espaciais.

Se com os $\mathrm{V} 2$ a guerra e a política foram elevadas para a atmosfera, a Guerra Fria, com seus mísseis e satélites, projetou-as para a órbita terrestre. A corrida espacial se deu em função da corrida armamentista. Acoplado ao espetáculo de 
demonstração de supremacia tecnológica para o grande público protagonizado pelo envio de satélites e humanos ao espaço, estava o interesse das superpotências aperfeiçoarem seus sistemas de lançamento de mísseis nucleares e de coletar informações sobre os arsenais atômicos inimigos. Longe dos olhos das populações, as superpotências construíram artefatos para serem instalados na órbita terrestre, os satélites artificiais, que permitiriam monitorar a potência bélica nuclear inimiga (Siqueira, 2018).

Retomar esse jogo de forças, de enfrentamento planetário e de ocupação da órbita terrestre com mísseis, foguetes e satélites permite observar o modo que as nascentes sociedades de controle ensaiaram a instauração de seus dispositivos de poder ligados ao monitoramento que estimulam controles, verificações e checagens contínuas para governar grandes multiplicidades em meio aberto.

Pesquisas apontam que os sistemas orbitais de monitoramento planetário inaugurados com o acontecimento sideral foram prioritariamente desenvolvidos para a inteligência militar, como meios destinados à coleta de informações sobre os arsenais nucleares detidos pelas superpotências (Day, 1998; Siqueira, 2018). O que não se imaginava é que, além de fazerem vigilância, eles colaborariam efetivamente para o governo do que parecia ingovernável e, desta forma, contribuiriam para impedir uma hecatombe nuclear que poderia dar fim ao planeta.

Desde o governo do presidente Harry Truman, a ameaça de um ataque nuclear surpresa comandado por soviéticos preocupava a sociedade estadunidense. Por questão de segurança nacional, os governos daquele país empenharam-se em buscar dados precisos sobre a real capacidade bélico-nuclear do inimigo. Apenas com a entrada em operação do Programa Corona de satélites de reconhecimento, em 1960, esses dados viriam a se tornar disponíveis. Além de possibilitar dados confiáveis, o emprego de satélites para o reconhecimento não implicava em violações à jurisdição da URSS, pois, com o advento da "Era Espacial", convencionou-se que nenhuma soberania se estenderia até o espaço, o que fazia da órbita terrestre mais uma área internacional de livre trânsito.

A quantidade de imagens produzidas pela primeira missão do programa Corona foi imensamente superior a todas as missões realizadas anteriormente pelos aviões U2, também desenvolvidos para fins de inteligência (Day, 1998). Até 1972, quando o programa foi encerrado, suas cerca de 145 missões produziram quase 650 quilômetros de filme, com o registro de mais de 800 mil fotos do território soviético (Wheelon, 1998). O mais importante é que essas imagens permitiram ao governo estadunidense ter certeza de que não estavam perdendo a corrida armamentista para os soviéticos. Com o passar dos anos, outros 
programas de reconhecimento substituíram o Corona e ampliaram a capacidade de os satélites de reconhecimento realizarem monitoramentos contínuos com envio de informações em tempo real.

Figura 2 - Imagem do satélite Corona, de 1962, localiza silos de mísseis na ex-URSS

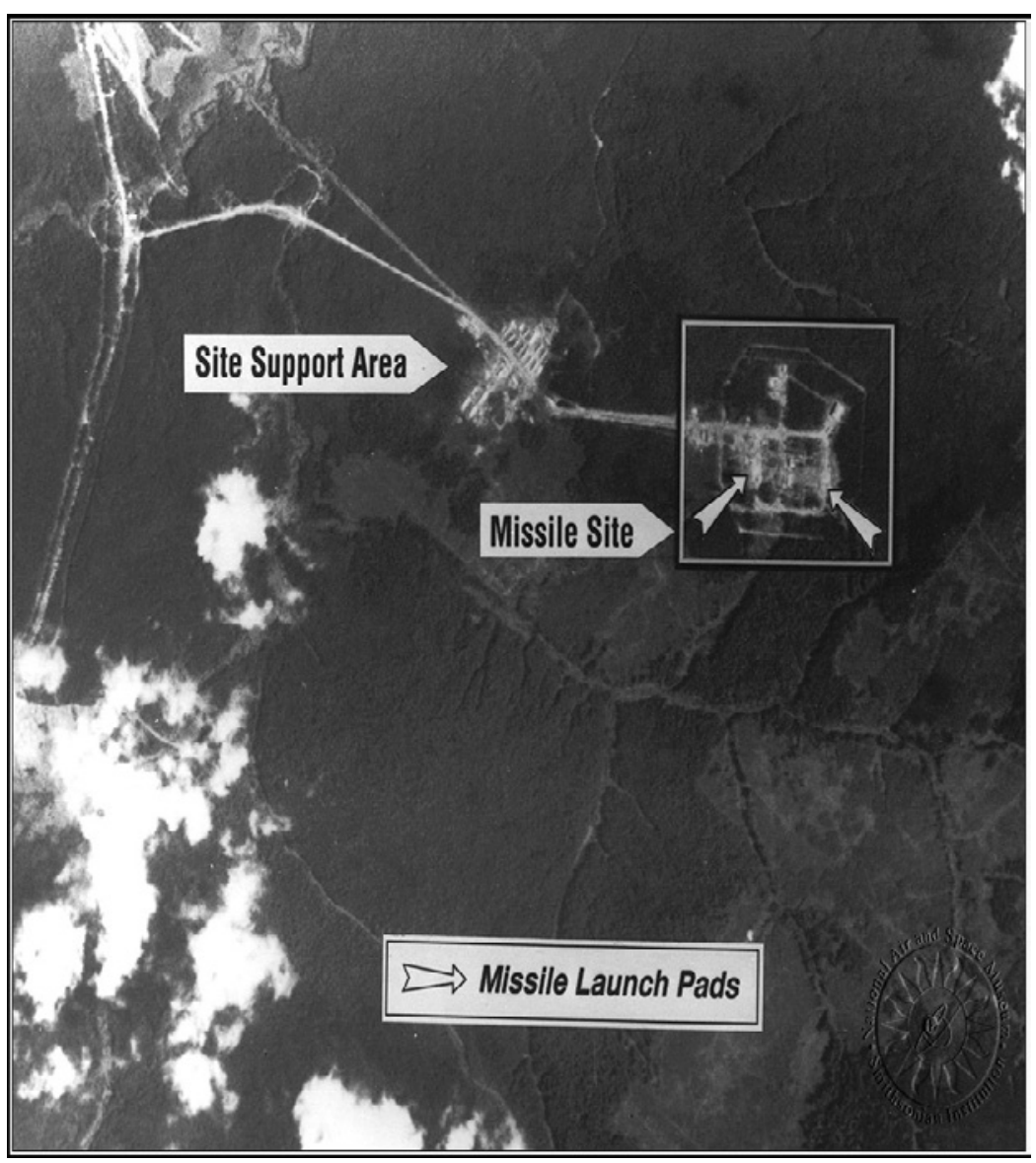

Fonte: USA National Reconnaissance Office

Foi por meio desse sistema de monitoramento recíproco, operado por programas de satélites desconhecidos do público até os anos 1990, que os arsenais nucleares puderam ser administrados e tiveram o seu risco "limitado". Apenas em 1977, os arsenais nucleares das superpotências se equipararam, com aproximadamente 25 mil ogivas cada. Embora possa parecer que estes acordos tenham fracassado, pois não tiveram êxito em impedir a proliferação das armas nucleares, sua efetividade deu-se no sentido de fornecer dados e informações e, desta forma, permitir que ambas as superpotências tivessem recíproco 
conhecimento do "tamanho" da ameaça nuclear. Deste então, com base em dados reais e não mais fundamentados em projeções, poderiam adotar outras estratégias para vencer a Guerra Fria que não o enfrentamento atômico, uma vez que a capacidade de "destruição mútua assegurada" obtida pelas superpotências as havia conduzido à impossibilidade de vencer o conflito pela força das armas.

Os satélites de reconhecimento impuseram transparência aos arsenais nucleares, efetivando, assim, a estratégia idealizada pelos EUA com a doutrina Open Skies, lançada pelo presidente Eisenhower, em 1955, que previa instauração de um regime de livre checagem entre as superpotências. Essas tecnologias espaciais colocaram em operação formas sistemáticas e, com o passar do tempo, contínuas, de verificação não apenas do cumprimento dos acordos de limitação de armas, mas também colaboraram para monitorar outras ações do inimigo, como o deslocamento de tropas pela superfície do globo. ${ }^{5}$

Desta forma, os satélites vieram a se efetivar como eficientes instrumentos para governar conflitos. Instauraram, assim, um regime de mútua verificação, de auditoria constante. Ao regularem os mísseis nucleares, assim como os conflitos espalhados pelo planeta, tornaram-se os artífices de uma paz que não é imposta pela vontade do mais forte e nem pela criação de consensos, mas que é calculada e mediada pelos envolvidos no conflito, uma "paz controlada".

Com o tempo, os sistemas de monitoramento inaugurados com a ocupação da órbita não ficaram restritos ao campo bélico. Eles passaram a ser aproveitados em outros campos não-militares à medida em que ficou evidente o seu potencial para identificar e rastrear o que se encontra sobre a superfície terrestre. Até as décadas finais do Século XX, seriam aplicados à meteorologia, ao sensoriamento remoto, à localização e ao controle da navegação (GPS).

Mais e mais as tecnologias espaciais são requisitadas para monitorar o planeta e têm se mostrado profícuas no atendimento às demandas colocadas pela expansão do capitalismo sobre o globo terrestre que, por sua vez, requer o monitoramento de uma quantidade cada vez superior de fluxos imprescindíveis para o seu funcionamento em escala planetária.

5 O recurso de monitoramento oferecido pelos satélites também foi utilizado pelas chamadas superpotências para a gestão diplomática e militar de conflitos em todo o planeta. As imagens de satélites lhes auxiliaram a tomarem decisões estratégicas durante os incidentes na fronteira sino-soviética (1961), na construção do muro de Berlim (1961), na Guerra dos Seis Dias (1967), na invasão soviética da Tchecoslováquia (1968), no avanço das tropas israelenses sobre o Canal de Suez (1973), nos conflitos nas Malvinas (1983), nas Guerras do Golfo Pérsico (1991), na Bósnia (1992), no Iraque (2003) e no Afeganistão (2001) (Villain, 2009). 
O estudo das tecnologias espaciais ajuda a evidenciar como as sociedades de controle foram beneficiadas pelo acontecimento sideral no que diz respeito ao desenvolvimento de sistemas de monitoramento do planeta. Além disso, seu estudo colabora para a compreensão de como funcionam os dispositivos de poder que operam a partir de checagens, verificações e controles contínuos para que o corpo do planeta possa ser governado não apenas por uma nação, mas por todos que venham dispor de tecnologias espaciais, tanto Estados como empresas.

Para essas sociedades, os monitoramentos afirmam-se como tecnologias indispensáveis para o exercício do governo de grandes multiplicidades a céu aberto, como convém ao controle. Os sistemas de monitoramento planetário são incidentais retornos do acontecimento sideral que alteraram a forma dos Estados administrarem a guerra, seus recursos naturais e até mesmo orientarem suas ações e interesses em relação a outros países. Como veremos a seguir, os retornos do acontecimento sideral também incidiram na relação estabelecida entre o humano e seu planeta, abrindo a possibilidade de este ser encorado como mais um corpo político a ser governado.

\section{2 - Um planeta a ser cuidado e gerido}

Dos pensadores que deram continuidade ao estudo das sociedades de controle desde Deleuze, Passetti não deixou de considerar sua conexão com o sideral e destacar o lugar singular que o Planeta Terra assumiu para o contemporâneo agenciamento coletivo. $\mathrm{O}$ autor afirma que, em decorrência da emergência de uma nova economia de poder que denomina ecopolítica, a Terra surgiu como um dos principais alvos dos investimentos políticos dessas sociedades. Ele vê na ecopolítica uma economia de poder transterritorial voltada para o controle sustentável dos ambientes, no qual as tecnologias de governo do vivente passariam a ser indissociáveis das estratégias para a majoração da saúde e da qualidade de vida do próprio planeta:

A qualidade de vida traduz em duas palavras a era da ecopolítica. Diante das quantidades acumuladas no passado de riqueza, pobreza, destroços e devastações, cada milímetro da Terra passa a ser alvo de conservação das espécies. A força das espécies, em especial da humana, é traduzida agora pela capacidade de certos segmentos atingirem qualidade em seus investimentos. De sorte que as populações e os Estados que ainda se orientem pelos princípios da quantidade devem sofrer intervenções pacíficas de administração e controle, chefiadas por organizações transnacionais, visando criar condições para o deslocamento para a qualidade ou guerras quando 
a atuação com base na quantidade gerar perigo para a qualidade de vida programada. Recursos naturais e derivados, principalmente sobre as fontes de energias, passam a ser os alvos preferenciais; eles precisam ser garantidos pelos que zelam pelo planeta, pelos que atingiram o patamar superior da consciência ecológica e, neste sentido, opõem-se a orientais, fundamentalistas, antigos parceiros ou aliados de outrora tradição. Os recursos naturais devem ser garantias planetárias administradas segundo os controles de fluxos eletrônicos mais avançados, podendo coincidir (o que é próprio desta época) ou não com nacionalidades. Exige-se um redimensionamento pacífico das armas destruição de propriedade de cada governo, através da fiscalização internacional capaz de firmar um compromisso de paz transnacional garantido, paradoxalmente, pelas potências bélicas mais equipadas (Passetti, 2003: 268, grifos do autor).

Na tentativa de se pensar o presente, a noção de ecopolítica conversa tanto com as análises deleuzianas quanto com as foucaultianas. Por meio dela, Passetti agregou mais um campo de problematização das transformações nas relações de poder sobre a vida, atualizando assim as análises de Michel Foucault (2005) sobre o biopoder. Diferentemente de outros autores, Passetti não trata a biopolítica como um conceito universal e, portanto, atemporal, mas procura evidenciar nos redimensionamentos relacionados à emergência das sociedades de controle mutações nos dispositivos de poder.

Ao dar prosseguimento à conversação sobre a transposição das sociedades disciplinares para as de controle, Passetti (2003) acrescentou que além do corpo-máquina e do corpo-espécie, identificados por Foucault (2005) como topos de incidência do biopoder, o controle agiria sobre o corpo-planeta, ou seja, sobre o corpo da Terra transformado em superfície aberta à inscrição das relações de poder. Entende que ao voltar-se para a majoração da vida e para a saúde do planeta, a ecopolítica cria programas inteligentes que visam a explorar os recursos naturais da Terra e, ao mesmo tempo, recuperar o que fora degradado pelo industrialismo depredador do capitalismo e do socialismo estatal. Passetti (2013) relaciona a ecopolítica planetária diretamente à produção da verdade capitalista sustentável, em elaboração desde a segunda metade do Século XX para impedir o colapso dos recursos naturais planetários, o que tornou urgente o monitoramento dos fluxos planetários para que o próprio capitalismo tenha continuidade.

Com base nesses desdobramentos expostos pela analítica passettiana, enfocaremos em como os retornos do acontecimento sideral colaboraram para a 
emergência do corpo-planeta. Configurado com fundamentação em múltiplos saberes produzidos desde a Segunda Guerra Mundial, o corpo-planeta decorre de conhecimentos provenientes da economia; do ambientalismo e da ecologia; das ciências dos sistemas (cibernética e computação); das ciências da Terra e da bioquímica; das engenharias (para a constituição de infraestruturas globais de comunicação, comércio, transportes), da guerra etc. $\mathrm{O}$ acontecimento sideral funcionou como um revestimento capaz de conectar todas essas disciplinas responsáveis por saberes que enfocam a interconexão dos elementos que compõem a Terra, além de forjar a utópica inteligibilidade de que o planeta, visto de seu exterior como um todo, seria um corpo passível ser administrado e governado.

Encontramos a ideia de que a Terra seria um corpo apto a ser administrado ou governado, por exemplo, na expressão Spaceship Earth (Espaçonave Terra), que fora imensamente propagada dos anos 1960 aos 1970. Presente de forma recorrente nos discursos de economistas, diplomatas, ambientalistas e "gurus" da contracultura, esta noção faz uma analogia da Terra a uma embarcação. Nesta maneira de compreender a Terra, reforça-se que ela não é apenas uma morada, mas o veículo no qual os viventes e a própria vida são conduzidos em sua jornada pelo infinito. Por este motivo, seriam extremamente dependentes deste veículo para que continuem a existir.

Ao reforçar o caráter "náutico" desta analogia da Terra, o economista estadunidense Kenneth Boulding colaborou para difundir a ideia de o planeta ser um sistema fechado, composto por elementos interdependentes, que, assim como uma nau, disporia de recursos restritos. Dizia que no Século XX a humanidade deveria se preparar para viver segundo os princípios de uma "economia astronauta", avessa a desperdícios e orientada para a otimização de suas fontes de subsistência (Boulding, 1966). Sob esta perspectiva, a Terra deixou de ser vista como uma fonte inesgotável de recursos naturais para emergir como um conjunto composto por recursos limitados, cujo uso deveria ser pautado pela racionalidade, a fim de evitar o esgotamento do planeta.

Um dos maiores propagadores da expressão Spaceship Earth foi o arquiteto Richard Buckminster Fuller, ícone da contracultura nos EUA. Além de realizar diversas palestras sobre o tema, Fuller escreveu, em 1969, o livro Manual de Instruções para a Nave Espacial Terra, no qual definiu a Spaceship Earth como um "veículo mecânico", cujo bom funcionamento estaria relacionado à capacidade de "ser compreendida e conservada na sua totalidade" (Fuller, 1998: 30). Para o arquiteto, modernos instrumentos como as teorias sistêmicas e os computadores seriam imprescindíveis para a administração deste veículo, já que ele havia saído de fábrica desprovido de seu "manual de utilização". 
Em outras de suas invenções, como o World Game, Fuller tentou dar mostras empíricas de como a Spaceship Earth poderia ser administrada: tecnologias avançadas, como computadores e satélites artificiais, auxiliariam no controle de diversas variáveis (população, estoque de recursos naturais, satisfação de necessidades humanas etc.) para que a humanidade pudesse viver em paz mediante a equitativa distribuição de riquezas e sem a necessidade de políticos ou militares (Fuller, 1971). Chama a atenção o fato de as criações de Fuller transparecerem ambições tecnocráticas de gestão não apenas de humanos, mas também das "coisas" necessárias para suprir suas necessidades. Note-se que o interesse de Fuller não se restringia ao território de um país, mas sua intensão estava em administrar a superfície de todo o planeta, visto como máquina a ser controlada.

Figura 3 - Nas invenções de Fuller, a concepção da Terra como espaçonave deixa transparecer ambições tecnocráticas

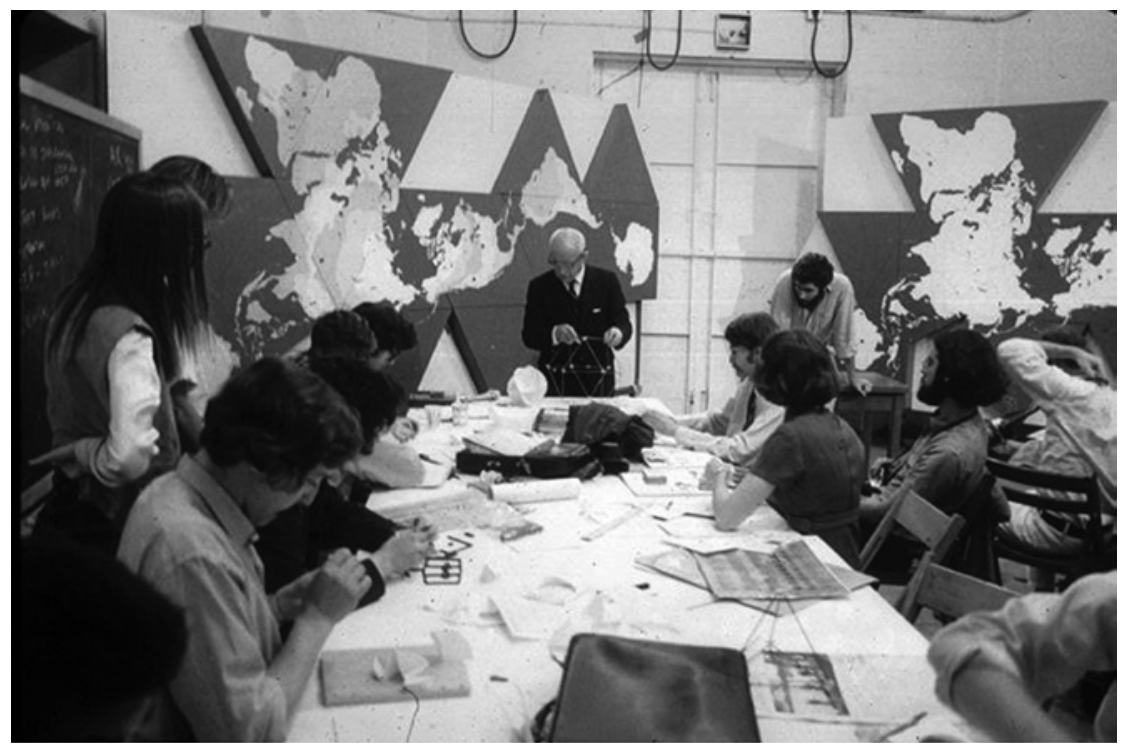

Fonte: The Buckminster Fuller Institute

Anos mais tarde, a noção de Spaceship Earth, embora não seja literalmente citada, embasou um dos principais documentos que pioneiramente alertou para o possível colapso das sociedades modernas devido ao rápido esgotamento dos recursos naturais do planeta, decorrentes do crescimento populacional, do industrialismo e da poluição. Publicado em 1972 pelo Clube de Roma, o relatório "Limites do Crescimento" tornou-se uma importante referência frente à escalada das questões ambientais e o debate internacional sobre o desenvolvimento 
socioeconômico dos países. No documento, o Clube de Roma não apenas se baseou no pressuposto de que a Terra seria um sistema fechado de recursos limitados, mas elaborou sua previsão catastrófica fundamentado em um programa de computador especialmente desenvolvido com a finalidade de oferecer cenários possíveis para o futuro da humanidade para então suscitar estratégias a fim de se evitar o pior. Inovadora, a experiência do Clube de Roma foi a primeira a utilizar tecnologia computacional para a modelização de fluxos planetários na tentativa de se antecipar cenários futuros de acordo com variáveis pré-selecionadas.

Ainda podemos encontrar a noção de Spaceship Earth, mas dessa vez de forma explícita, em outro relatório também lançado no ano de 1972, o "Only one Earth: The Care and Maintenance of a Small Planet", elaborado especialmente para subsidiar a Conferência das Nações Unidas sobre o Ambiente Humano, realizada em Estocolmo. Nele, seus autores apresentaram os objetivos e os desafios que motivaram a realização daquela que foi considerada a primeira cúpula da Terra: "formular os problemas inerentes às limitações da espaçonave Terra e projetar padrões de comportamento coletivo compatíveis com o continuado florescer de civilizações" (Ward; Dubos, 1973: 26). Neste livro, a proposta de gestão da Terra não soa mais como uma utopia tecnocrática como aparecera em Fuller, mas apresentou-se como uma demanda urgente reclamada por movimentos ambientalistas, cientistas e representantes de países para a proteção do planeta.

Figura 4 - Imagens da Terra vista de seu exterior ilustram a capa dos dois livros lançados em 1972, que concebem o planeta como um sistema fechado: Spaceship Earth
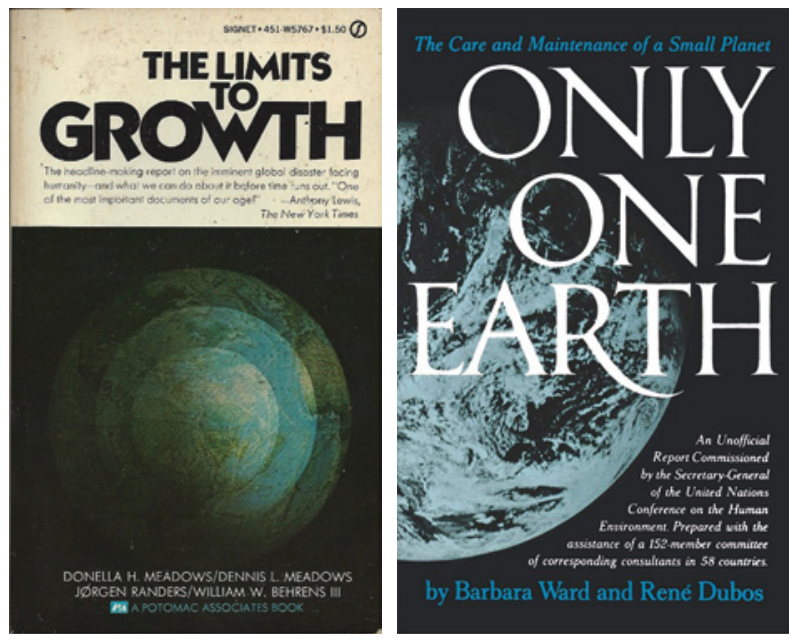

A percepção de que a Terra seria um frágil planeta, nascida quando astronautas registraram suas primeiras imagens, também contribuiu para reforçar a 
inteligibilidade que pretende fazer da Terra um corpo passível de ser "cuidado" e administrado. Durante as missões Apollo de viagem à Lua, realizadas de 1968 a 1972, pela NASA, os astronautas puderam visualizar a Terra de uma perspectiva jamais vista, e a imortalizaram em fotografias em que aparece inteira, em toda a sua plenitude, tornando-a visível para a humanidade.

Duas dessas fotografias se tornaram célebres: a Earthrise, de 1968, e a Blue Marble, de 1972. Essas imagens tiveram um inusitado impacto sobre a opinião pública mundial, vindo posteriormente a figurar entre as imagens mais reproduzidas em toda a história. Elas apresentaram uma Terra que, graças à perspectiva exterior, poderia ser observada com seus limites bem definidos, como um corpo único, como uma "pequena" e "frágil" bola flutuando no escuro do universo, conforme a descrição dos astronautas da missão Apollo. Ao mesmo tempo em que despertaram sentimentos de unidade e de pertencimento, a recepção dessas imagens chamou atenção para a vulnerabilidade do planeta (Grevsmühl, 2014; Poole, 2008). Elas exerceram um especial apelo sobre o novo ambientalismo, sendo rapidamente incorporadas como suas bandeiras (McCormick, 1992). Foram responsáveis por impulsionar as lutas ambientalistas de um contexto local ou nacional para o planetário, enfatizando que a proteção da natureza também significava a defesa do planeta Terra como um todo.

As imagens da Terra inteira também foram capazes de estimular utopias gestionárias em relação ao planeta que outrora parecia ser imenso, mas que desde então aparentava poder ser pego em uma mão, como afirmou um dos astronautas das missões Apollo. A partir de 1972, com a instalação de satélites de sensoriamento remoto na órbita terrestre, essas utopias começaram a se tornar factíveis, graças à capacidade das tecnologias espaciais fornecerem cobiçadas imagens que passaram a ser utilizadas pelos países na gestão de extensas áreas da superfície terrestre. ${ }^{6}$

Por fim, o último elemento que destacamos a partir do acontecimento sideral para a configuração do corpo-planeta vem do campo da astrofísica e da bioquímica: a hipótese Gaia. Elaborada pelo cientista britânico James Lovelock ao longo dos anos 1970 e 1980, a hipótese Gaia defende que a Terra deva ser vista

6 O sistema LANDSAT de satélites de sensoriamento remoto da Terra teve início em 1972 e continua em operação até hoje. Durante os últimos 40 anos, esses satélites coletaram informações sobre a Terra que foram utilizadas pelos Estados Unidos para a cartografia, a gestão da agricultura, de florestas, a exploração de recursos hídricos e terrestres (minerais, características do solo etc.), a instalação de indústrias, criação de infraestruturas pelo território, urbanismo etc. Este conjunto de dados reunidos formam o maior arquivo histórico dos efeitos das mudanças e intervenções humanas sobre a natureza, bem como das manifestações das forças telúricas que afetaram a Terra. 
em seu conjunto como um ser vivo, um imenso organismo. Essa proposta surgiu da confluência dos saberes cibernéticos, bioquímicos e geocientíficos, que embasaram o pensamento do cientista. Em seus trabalhos, Lovelock destaca que lhe fora indispensável a perspectiva sideral, observar a Terra de seu exterior, o que fizera quando trabalhou para a NASA no fim dos anos 1960, para conceber a possibilidade de o planeta ser um organismo vivo:

Foi preciso ver a Terra do espaço, quer dizer directamente, através dos olhos dos astronautas, quer por delegação, fazendo uso dos meios de comunicação visuais, para que formássemos a noção de um planeta vivo, no qual as coisas vivas, o ar, os oceanos, as rochas, tudo se transformava numa coisa só: Gaia.

(Lovelock, 1988: 36).

Com sua hipótese, Lovelock atualizou os conhecimentos geofísicos do início do Século XX, que descreviam a Terra como um conjunto de esferas sobrepostas (atmosfera, hidrosfera, litosfera e biosfera), conforme a proposta do geoquímico russo Vladimir Vernadsky. Com base em seu olhar cibernético, o cientista postulou não haver separação entre matéria inorgânica e orgânica na composição do planeta, mas que ambas formavam um todo sistêmico capaz de se autorregular e, assim, dotar de vida o grande organismo que é a Terra (Lovelock, 2000).

Ao atribuir à Terra um caráter biosistêmico, a hipótese Gaia reforçou a alternativa de se pensar que intervenções poderiam ser tomadas para "melhorar" os fluxos planetários, no sentido de impedir que a ação humana alterasse a capacidade de a Terra abrigar a vida.

Por meio das noções de SpaceshipEarth, de planeta vulnerável e da hipótese Gaia, podemos evidenciar o modo como as sociedades de controle recorreram a diversos saberes que, ao serem revestidos pelo acontecimento sideral, configuraram uma nova inteligibilidade para o humano pensar e agir sobre o seu planeta natal. Desde então, a Terra nasceu aos olhos humanos como um planeta pequeno, com recursos limitados e frágil, do qual dependem os humanos para sobreviverem. E mais, durante o percurso de elaboração destes saberes telúricos, o planeta ganhou vida, passando a ser compreendido como um sistema de inúmeros elementos interconectados, tal qual um organismo que se autorregula para manter-se vivo.

Essas novas percepções foram decisivas para que a Terra viesse a ser vista como um corpo cujo estado de vulnerabilidade demandaria proteção e cuidados em relação à sua saúde. Se o acontecimento sideral, por um lado, despertou 
sentimentos de preocupação e compaixão pelo planeta, por outro, ele também acenou com a promessa de oferecer meios para exercer este "cuidado", mediante o desenvolvimento de tecnologias para o monitoramento dos "sinais vitais" do planeta pela órbita terrestre. Mediante a disponibilidade de um sistemático acompanhamento das causas do "adoecimento", este corpo poderia ter sua saúde continuamente tratada. ${ }^{7}$

Esta série de deslocamentos no modo das contemporâneas sociedades conceberem a Terra expõem mutações das economias de poder que abrem novos campos de possibilidades para o governo. Através dela, podemos observar a emergência do corpo-planeta. Compreendemos o corpo-planeta como a interface digital configurada pelas sociedades de controle com a pretensão de administrar, regular e governar os mais diversos fluxos planetários. Ele alimenta-se da contínua e sistemática coleta de informações e dados sobre a Terra, efetuada pelas tecnologias planetárias de monitoramento, sobretudo aquelas instaladas na órbita terrestre. Esse conjunto exponencialmente crescente de Big Data telúrico produz um duplo computo-informacional da Terra que se sobrepõe à superfície terrestre, sendo utilizado pelas sociedades de controle para produzir projeções, cenários e modelizações do passado, do presente e do futuro do planeta. Com a emergência do corpo-planeta, inauguram-se novas modalidades de governo dos viventes e das coisas que buscam atender urgências colocadas pela necessidade de gestão planetária, sob a demanda da racionalidade neoliberal de um capitalismo em expansão para toda a superfície terrestre e que já ensaia deixar a Terra. ${ }^{8}$

\section{3 - Governamentalização do planeta e racionalidade neoliberal}

Dentre os retornos do acontecimento sideral, procuramos analisar aquele que consideramos ser um dos mais expressivos para a configuração do

7 A agência espacial estadunidense possui um departamento, o NASA Earth System Science, inteiramente voltado para entender como interagem atmosfera, litosfera, hidrosfera, criosfera e a biosfera, formando um sistema conectado, conjunto ao qual denomina "Sistema Terra". Sua finalidade é compreender cientificamente o sistema da Terra e suas reações a mudanças naturais ou àquelas provocadas pelo humano. Um dos principais componentes deste programa é a constelação de satélites da NASA projetados para observações globais de longo prazo. Disponível em: <https://science.nasa.gov/earth-science>. Acesso em: 02 jun. 2019.

8 Pelo menos duas empresas anunciaram que pretendem minerar de asteroides próximos à Terra. Em 2016, o governo dos EUA editou a primeira legislação que permite a exploração de asteroides com vistas à apropriação privada de lucros, embora a determinação contrarie acordos internacionais que preveem que nenhum corpo celeste poderia ser apropriado por uma nação, pois o espaço exterior é considerado um bem de toda humanidade. 
diagrama das sociedades de controle. Ao identificarmos a emergência do corpo-planeta, pretendemos destacar a entrada da Terra no alvo de disputas políticas que visam a conciliar a continuidade do desenvolvimento capitalista e os efeitos devastadores da produção industrial para o planeta (esgotamento de recursos naturais, poluição, degradação ambiental etc.). Trata-se de disputas que estrategicamente consideram o extremo grau de interconexão das atuais sociedades por toda a superfície planetária e, ao mesmo tempo, a ameaça de uma iminente catástrofe que poderia colocar em risco a existência da vida humana.

É dentro deste contexto de recobrimento do corpo da Terra por essas relações de poder que podemos compreender, por exemplo, a proposta lançada pelo químico Paul Crutzen e do biólogo Eugene Stoermer, de que viveríamos em um novo período geológico da Terra, o Antropoceno. Crutzen e Stoermer (2000) argumentam que a humanidade teria se tornado uma verdadeira força geológica capaz de alterar o funcionamento do planeta. Pela primeira vez em sua história, o planeta não seria transformado exclusivamente por forças naturais (formação de rochas e dos oceanos, erupção de vulcões, deslocamento de placas tectônicas, glaciação etc.); mas na origem das atuais perturbações do sistema climático planetário e da deterioração do equilíbrio da biosfera.

A hipótese do Antropoceno é apenas um dos exemplos que poderíamos elencar para evidenciar o processo de governamentalização do planeta, dentro do qual nos interessa ressaltar o papel desempenhado pelo acontecimento sideral. Porém, antes de desenvolvermos mais esse argumento, cabe-nos pontuar o que entendemos por governamentalidade.

Foucault apresentou a noção de governamentalidade durante as aulas do curso "Segurança, Território, População", ministrado no Collège de France, no biênio 1977-1978, definindo-a como:

o conjunto composto por instituições, procedimentos, análises e reflexões, os cálculos e as táticas que permitem exercer essa forma bem específica, ainda que complexa, de poder que tem por alvo principal a população, por forma maior de saber a economia política, por instrumento técnico essencial os dispositivos de segurança (Foucault, 2008: 143).

Neste momento, interessava ao filósofo compreender, não por meio da teoria, mas analisando práticas, como, a partir do Século XVI, o Estado Moderno fora governamentalizado. Dizer que o Estado passou por um processo de governamentalização significa dizer que nem sempre o governo fora uma atribuição do soberano. Isto é o que mostra Foucault quando encontra na religião cristã e, mais especificamente, no pastorado, a procedência da arte de governar 
desenvolvida pelas monarquias europeias na Idade Moderna: a razão de Estado. Com o advento do Estado Moderno, o rei passou a exercer o poder pastoral, aos moldes do sacerdote medieval, incumbira-se de zelar por cada ovelha, assim como por todo o rebanho, devendo prover-lhes meios de subsistência para que seu bem-estar também contribuísse para o esplendor do Estado. Portanto, quando o autor utiliza a palavra governamentalizar, refere-se ao processo pelo qual o Estado assume o protagonismo de governar cada indivíduo e a coletividade, por meio da condução das condutas de cada um e de todos, momento em que o exercício do poder na forma governo colmatou-se ao poder soberano.

Como afirma o sociólogo Thomas Lemke, o estudo das governamentalidades diz respeito à análise de como uma específica racionalidade política funciona enquanto "'política da verdade', produzindo novas formas de conhecimento, inventando diferentes noções e conceitos que contribuem para o governo de novos domínios de regulação e intervenção" (2017: 202). Ainda no curso "Segurança, Território, População", Foucault recuperou a emergência, no Século XVIII, de outra governamentalidade, não mais identificada com a razão de Estado, mas com a racionalidade liberal. Essa nova forma de governar não procuraria mais intensificar o Estado. Pelo contrário, agiria no sentido de limitá-lo, de restringir suas intervenções autoritárias, ajustando-o a partir de uma nova verdade, o mercado, e um novo saber, a economia política.

No curso "Nascimento da Biopolítica", de 1979, Foucault prosseguiu com suas pesquisas sobre governamentalidade. Só que desta vez abordou o neoliberalismo enquanto uma racionalidade política que faria uso de tecnologias ambientais para ampliar liberdades e, ao mesmo tempo, regular o jogo estabelecido entre interesses individuais e coletivos. Em suas considerações, aponta que a racionalidade neoliberal se notabiliza pela extensão da lógica do mercado, estimulada pela concorrência e pela proliferação do modelo da empresa privada a outros âmbitos da vida (Foucault, 2004). Neste sentido, definiu o neoliberalismo (principalmente o estadunidense) como um modo de ser e agir orientado por uma grade de pensamento que prioriza cálculos e probabilidades para a otimização de custos e benefícios, a fim de reduzir riscos e majorar os ganhos de acordo com os interesses dos indivíduos-empresas. Como apontam Dardot e Laval (2013), a racionalidade neoliberal se destaca por sua transversalidade, procurando reconfigurar as relações sociais em diferentes esferas da existência, do econômico ao social, além de atravessar os mais diferentes níveis, do local ao global.

$\mathrm{O}$ acontecimento sideral reverbera a transversalidade da racionalidade neoliberal, incluindo em sua grade de pensamento, como diria Foucault, ou em sua 
política da verdade, como diria Lemke, o Planeta Terra. É neste sentido que podemos afirmar que entre os mais interessantes e inesperados retornos do acontecimento sideral, do ponto de vista político, está a governamentalização do planeta.

A análise da governamentalização do planeta visa justamente a destacar o processo pelo qual a Terra, com seus fluxos de elementos inorgânicos e orgânicos, tomados em interfaces que conectam humanos e não humanos, tornou-se um "problema" que demanda da racionalidade política certos dispositivos de poder que possibilitem pensar e tornar factível o seu governo. Vemos, portanto, na governamentalização do planeta uma resposta da racionalidade neoliberal ao ter sido desafiada não apenas pelo fator "escala", mas também pela complexa interconexão colocada pela expansão do capitalismo para o globo terrestre. Mais do que uma contraposição, vemos entre governamentalização do planeta e racionalidade neoliberal uma relação de complementariedade, que coloca em relevo uma reconfiguração do próprio neoliberalismo quando este passa a operar globalmente.

Observar a governamentalização planetária significa verificar como o avanço do neoliberalismo nas sociedades de controle recobre a Terra, transformando-a em um corpo a ser decifrado e compreendido por meio de análises que priorizam cálculos de custo-benefício ou de probabilidades de riscos para otimizar "ganhos" ou "melhorias" telúricas. Neste processo, as tecnologias espaciais possuem um papel ímpar não apenas por terem propiciado visualizar a Terra, mas também por fornecerem dados e informações que fundamentam saberes científicos sobre o planeta, segundo os quais as sociedades de controle selecionam campos para regulação e intervenções em escala planetária. Embora sejam orientadas para o nível macro, essas intervenções também afetam diretamente os âmbitos locais, nacionais e regionais, como vemos ocorrer, por exemplo, a propósito das Mudanças Climáticas.

Desde as décadas finais do Século XX, saberes científicos transformaram os gases do efeito estufa em praticamente "unidades contábeis" utilizadas para mensurar o aquecimento das temperaturas globais, tendo no Painel Intragovernamental das Mudanças Climáticas das Nações Unidas (IPCC, na sigla em inglês) a principal instância responsável pelo monitoramento das transformações climáticas do planeta. Além de certificar os dados climáticos sobre a Terra, o IPCC estabeleceu-se como um importante polo difusor de políticas climáticas globais e nacionais, ao propor metas de redução de emissões dos gases do efeito estufa com a finalidade de assegurar condições ideais para que o Sistema Terra continue a abrigar a vida no planeta, sem a necessidade de romper com o modo de produção capitalista. 
Analisar a projeção da racionalidade neoliberal para o planeta, tendo este sido incluído em sua política da verdade, exige que prestemos atenção a mais um aspecto originalmente observado por Foucault sobre a governamentalidade. No centro da problemática que desenvolveu estava o propósito de abordar a prática de governo das populações sem que esta fosse confundida com o exercício da soberania e nem com a criação de instâncias de dominação. Longe de ser caracterizado como uma forma de poder que age pela coerção, o governo é compreendido pelo filósofo como maneiras de "conduzir as condutas dos homens" (Foucault, 2001: 1056), estrategicamente tomadas no sentido de favorecer que o alvo das práticas de governo (ser ou coisa) venha a realizar sua finalidade, em favor de seu bem-estar. Como observou a respeito do biopoder, o governo se dá na confluência do indivíduo com a população, envolvendo relações para consigo (governo de si) e relações entre sujeitos (governo dos outros). Neste sentido, o poder de gerir a vida comporta tecnologias individualizantes e totalizantes, voltadas para agir sobre o corpo e sobre a espécie humanos (Foucault, 2005). Portanto, estudar uma específica governamentalidade requer a investigação de tecnologias de poder que combinam "complexas técnicas de individuação" e "procedimentos totalizadores" (Foucault, 1982: 1051).

Desde o acontecimento sideral, o Planeta Terra figura como mais um elemento da política da verdade que atravessa os processos de individuação e de totalização nas sociedades de controle. A Terra, seus recursos naturais, os efeitos da ação humana sobre a biosfera tornaram-se fatores relevantes para o comportamento de cada indivíduo, empresa ou Estado. Proteger espécies em extinção, preferir tecnologias limpas às poluentes, fazer coleta seletiva, utilizar de forma racional os recursos naturais, preservar a camada de ozônio, regular as emissões de $\mathrm{CO}_{2}$ etc. são formas de se comportar em relação a si e aos outros estimuladas pelo agenciamento coletivo que fez da Terra uma nova superfície para a inscrição das relações de poder. Mais do que isso, desde as últimas décadas do Século XX, o cuidado com o planeta é encarado como uma responsabilidade de indivíduos, empresas e países. Todos devem colaborar para "salvar" a Terra. Deste modo, a preocupação com a Terra passou a integrar os contemporâneos processos de subjetivação, sendo indissociável dos processos de constituição dos sujeitos na contemporaneidade.

Tal como ocorrera em outros momentos históricos em relação à religião e ao Estado, hoje o planeta deve ser levado em conta em cada mínima ação desempenhada. "Pensar globalmente, agir localmente" é o slogan oriundo do meio ambientalista e da ecologia política que melhor expressa esta nova tecnologia 
de subjetivação desenvolvida pelas sociedades de controle que busca incorporar o planeta ao escopo de ação de cada indivíduo, de toda a sociedade, integrando sistemicamente o micro ao macro, condutas pessoais a políticas internacionais. Observamos essa política da verdade, por exemplo, nas iniciativas da Organização das Nações Unidas de incentivar a adoção de planos de ação para indivíduos, empresas e Estados, como a Agenda 21 Global, lançada em 1992, durante a ECO-92 e, mais recentemente, a Agenda 2030 para o Desenvolvimento Sustentável, que determina 17 objetivos globais para garantir a paz e prosperidade. Nessas agendas, a proteção da Terra aparece como um compromisso a ser assumido por todos:

Estamos determinados a proteger o planeta da degradação, sobretudo por meio do consumo e da produção sustentáveis, da gestão sustentável dos seus recursos naturais e tomando medidas urgentes sobre a mudança climática, para que ele possa suportar as necessidades das gerações presentes e futuras (Nações Unidas, 2015).

Figura 5 - A modelo australiana Renee Somerfield pousa para campanha em defesa do veganismo promovida pela ONG PETA: salvação do planeta na pele e nas mínimas condutas individuais.

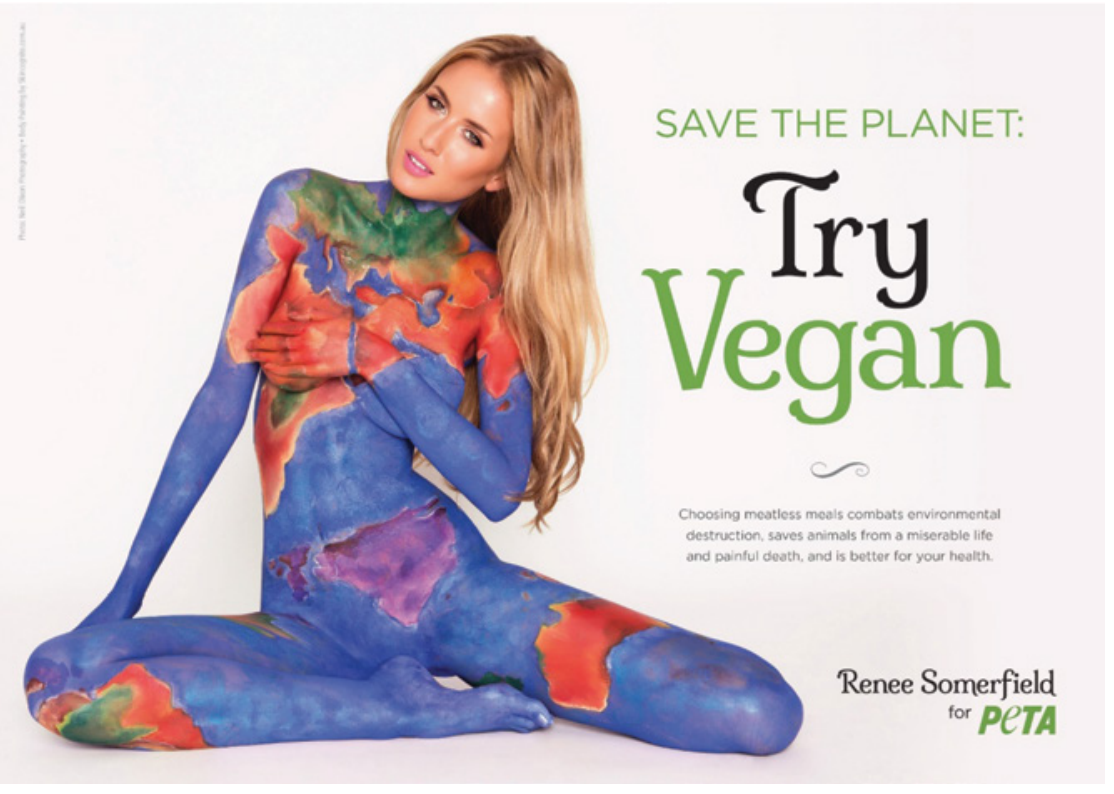




\section{Apontamentos finais}

Quando o beep beep emitido pelo Sputnik 1, o primeiro satélite artificial lançado ao espaço, em 1957, foi ouvido em todo o planeta, anunciando o acontecimento sideral, imaginava-se que o futuro estaria nas estrelas e não tardaria para que outros mundos fossem colonizados.

Foi preciso algumas décadas para se perceber que, por mais distante que astronautas ou sondas espaciais tenham chegado, não seria simples prescindir da Terra. Pelo contrário, parte desta grande aventura voltou-se para fazer deste planeta mais um corpo a ser observado, cuidado e governado, graças às possibilidades trazidas pelas tecnologias espaciais. As contemporâneas sociedades reorientaram seus investimentos políticos para também abranger o corpo-planeta, atualizando, assim, a biopolítica das sociedades disciplinares que tinham como estratégia ampliar a vida do corpo-espécie dentro dos limites do Estado-nação.

Como pano de fundo deste acontecimento, para além de imagens da Lua e da Terra, podemos verificar mutações nas relações de poder. Graças à perspectiva sideral, as contemporâneas sociedades gestaram seus novos mecanismos de poder voltados para o governo a céu aberto. No centro deste céu, a Terra.

Longe de distanciar o humano de seu planeta, o acontecimento sideral fez da Terra sua extensão. Nas sociedades de controle, o exercício da política sobre a vida se faz em interface com o planeta.

\section{Referências}

BOULDING, Kenneth. The Economics of the Coming Spaceship Earth. In: Jarrett, H.

(Ed.) Environmental Quality in a Growing Economy: Essays from the Sixth Resources for the Future Forum. Baltimore, Johns Hopkins Press, 1966.

COSGROVE, Denis. Contested Global Visions: One-World, Whole-Earth, and the Apollo Space Photographs. Annals of the Association of American Geographers. $\mathrm{n}$. 84, 1994, pp. 270-294.

CRUTZEN, Paul J.; STOERMER, Eugene F. The "Anthropocene". Global Change Newsletter. 41, 2000, pp. 17-18.

DAY, Dwayne. The development and Improvement of CORONA Satellite. In: DAY, Dwayne, LOGSDON, John e LATELL, Brian (Eds.). Eye in the Sky: the story of the Corona spy satelites. Washington e London, Smithsonian Institution Press, 1998, pp. 48-85.

DARDOT, Pierre; LAVAL, Christian. The new way of the world. London/New York, Verso, 2013.

DELEUZE, Gilles. Foucault. Paris, Les Éditions de Minuit, 1986. 
. Pourparlers 1972-1990. Paris, Les Éditions de Minuit, 1990.

. El poder: curso sobre Foucault II. Tradução de Pablo Ariel Ires. Buenos Aires, Cactus, 2014.

FOUCAULT, Michel. Microfísica do poder. Rio de Janeiro, Graal, 1979.

. Le sujet e le pouvoir. In: Dits et écrits, v. 2. Paris, Gallimard, 20, pp. 1041-1062.

. Naissance de la biopolitique. Cours au Collège de France (1978-1979). Paris, Seuil/

Gallimard, 1994.

. Naissance de la biopolitique. Cours au Collège de France (1978-1979). Paris, Seuil/

Gallimard, 2004.

. História da Sexualidade I: A vontade de saber. 16 ${ }^{\mathrm{a}}$ ed. São Paulo, Graal, 2005.

. Segurança, Território, População. Curso dado no Collège de France (1977-1978).

São Paulo, Martins Fontes, 2008.

. Du gouvernement des vivants. Cours au Collège de France (1978-1979). Paris, Seuil/Gallimard, 2012.

FULLER, Richard Buckminster. World Game Series: Document One. The World Game:

Integrative Resourse Utilization Planning Tool. Illinois, World Resources Inventory Southern Illinois University Carbondale, 1971.

. Manual de Instruções para a Nave Espacial Terra. Porto, Via Optima, 1998.

GREVSMÜHL, Sebastian Vincent. La Terre vue d'en haut. L'invention de l'environnement global. Paris, Seuil, 2014.

LEMKE, Thomas. Foucault, governamentalidade e crítica. Plural. v. 24.1, pp. 194-21, 2017.

LOVELOCK, James. As Eras de Gaia: uma biografia do nosso planeta vivo. Mira-Sintra,

Publicações Europa-América, 1988.

. Gaia, A New Look at Life on Earth. New York, Oxford University Press, 2000.

MÉLANDRI, Pierre. Imaginer l'inimaginable. Guerre nucléaire et stratégie américaine depuis 1945. Vingtième Siècle. Revue d'histoire, n. 1, janvier, 1984, pp. 57-74.

MEADOWS, Donella; MEADOWS, Denis; RANDERS, Jorgen ; BEHRENS, W. Limites do Crescimento: Um Relatório para o Projeto do Clube de Roma sobre o Dilema da Humanidade. São Paulo, Perspectiva, 1972.

MCCORMICK, John. Rumo ao paraíso: a história do movimento ambientalista. Rio de Janeiro, Relume-Dumará, 1992.

NAÇÕES UNIDAS. Transformando Nosso Mundo: A Agenda 2030 para o Desenvolvimento Sustentável, 2015. Disponível em: <https://nacoesunidas.org/ pos2015/agenda2030/>. Acesso em: 20 maio 2019.

PASSETTI, Edson. Anarquismos e sociedade de controle. São Paulo, Cortez, 2003. . Transformações da biopolítica e emergência da ecopolítica. Revista Ecopolítica. n. 5, 2013, pp. 81-116.

SIQUEIRA, Leandro A. de P. Ecopolítica: derivas do espaço sideral. Tese de Doutorado. 
Programa de Estudos Pós-graduados em Ciências Sociais, Pontifícia Universidade Católica de São Paulo, São Paulo, 2015, 430 p. . Bring data! Corrida espacial e inteligência. Diálogos. v. 22, 2018, pp. 76-90.

POOLE, Robert. Eathrise: How Man First Saw the Earth. New Haven, Yale University Press, 2008.

WARD, Barbara; DUBOS, René. Uma terra somente. São Paulo, Melhoramentos; Ed. da Universidade de São Paulo, 1973.

WHEELON, Albert. CORONA: A Triumph of American Technology. In: DAY, Dwayne; LOGSDON, John; LATELL, Brian (Eds.). Eye in the Sky: the story of the Corona spy satellites. Washington e London, Smithsonian Institution Press, 1998, pp. 29- 47.

VILLAIN, Jacques. Satellites Espions: histoire de l'espace militaire mondial. Paris, Vuiber/ Ciel\&Espace, 2009.

Recebido em 18/01/2019 Aprovado em 18/06/2019

\section{Como citar este artigo:}

SIQUEIRA, Leandro. Acontecimento sideral e a governamentalização do planeta: notas sobre a atualizações dos dispositivos de poder nas sociedades de controle. Contemporânea - Revista de Sociologia da UFSCar, v. 9, n. 1, jan.- jun. 2019, pp. 11-35. 